Vol. 2, No. 3, pp. 178-189, (September2021)

DOI: 10.21608/aujes.2021.77260.1025

Aswan University Journal of Environmental Studies (AUJES)

Online ISSN: 2735-4237, Print ISSN: 2735-4229

Journal homepage: https://aujes.journals.ekb.eg/

E-mail: AUJES@aswu.edu.eg

Original research

Preparation and characterization of nanocrystalline $\mathrm{NiO}$ by the thermal decomposition of oxalate salt for the dehydrogenation of 2-butanol to methyl ethyl ketone

\author{
Abouelhassan A. Gomaa, Adel Abdelkader*, Samih A. Halawy and Mohamed A. Mohamed \\ Chemistry Department, Faculty of Science at Qena, South Valley University, Qena 83523, Egypt
}

Received: $26 / 5 / 2021$

Accepted: 28/7/2021

(C) Unit of Environmental Studies and Development, Aswan University

\begin{abstract}
:
In the present study, highly active nanocrystalline nickel oxide samples were prepared by using a simple, solvent-free and cost-effective preparation method. Commercial nickel oxalate dihydrate powder was mixed with deionized water to form a soft paste which was sonicated till dryness and then, calcined in static air. The prepared nickel oxide samples were characterized by means of Fourier transform infrared spectroscopy (FT-IR), X-ray diffraction (XRD), scanning electron microscopy (SEM) and N2 adsorption-desorption techniques. Surface basicity of the prepared oxide samples was measured by adsorption of $\mathrm{CO}_{2}$ molecules followed by desorption measurements using thermogravimetry (TG) technique. Catalytic activity of the prepared nickel oxide samples towards the dehydrogenation of 2-butanol to methyl ethyl ketone (MEK) was studied at a temperature range of $225-325^{\circ} \mathrm{C}$. The effects of calcination temperature, reaction temperature and weight hourly space velocity (WHSV) on the catalytic activity was studied to determine the best calcination temperature and the optimum operation conditions. The sample calcined at $400^{\circ} \mathrm{C}$ showed the highest activity and the optimum operation conditions were found to be at reaction temperature of $300^{\circ} \mathrm{C}$ and WHSV of $15 \mathrm{~L} \mathrm{~h}^{-1} \mathrm{~g}^{-1}$. The selectivity to MEK was higher than $85 \%$ for all the conducted experiments.
\end{abstract}

Keywords: Nickel oxalate dihydrate; NiO; Basic site densities; 2-butanol; methyl ethyl ketone.

\title{
1- INTRODUCTION
}

Nickel oxide $(\mathrm{NiO})$ is a ferromagnetic crystalline solid material with unique magnetic, electrical, and optical properties that make it the main subject of a large number of research studies (Zhao et al., 2016 ) It is one of the most important and promising low-cost transition metal oxides due to its physical and chemical properties that make it suitable for many applications. The applications of nickel oxide include catalysis, electrochemistry, p-type transparent conducting films, and water treatment (Bonomo., 2018; Zhang S et al., 2017; Zhou et al., 2017; Lu et al., 2017; Zhang et al., 2016; Al-Ghamdi et al., 2016; Wang et al., 2015; Bodurov et al., 2014; Abbasi et al., 2013).

Corresponding author*: E-mail address: abou.gomaa10@gmail.com 
The the catalytic activity and performance of $\mathrm{NiO}$ in many applications depends mainly on its some important characteristics includes crystalline phase state, dimension and morphology (Kundu et al., 2017). There are many morphologies of $\mathrm{NiO}$ that were fabricated, such as nanorods, nanosheets, microspheres, hierarchical hollow nanostructures, and nanowires (Halawy et al., 2018; Zhang et al., 2017; Li et al., 2017; Zhang Y., 2015; Tyagi et al., 2014).

The preparation of nickel oxide can be carried out by different pathways using different nickel precursors. One of the simplest methods for the preparation of nickel oxide is the direct calcination of nickel-containing precursors such as carbonates, nitrates, oxalates, etc. In the present study, nickel oxide was prepared by the calcination of nickel oxalate dihydrate at 400, 500 and $600^{\circ} \mathrm{C}$. In general, thermal decomposition of nickel oxalates dihydrate to nickel oxide proceeds in two main stages, i.e. dehydration and decomposition. However, the dehydration and decomposition steps of nickel oxalates dihydrate were found to be influenced by various factors such as the heating rate and mass of the sample (Mohamed et al., 2005; Mansour., 1993; Yong and Hall., 1989; Alloun and Nair., 1985; Mu and Perlmutter., 1981;). In general, thermogravimetry (TG), differential thermal analysis (DTA) and differential scanning calorimetry (DSC) are the most commonly used techniques for studying the process of dehydration-decomposition of metal oxalates.

One of the most important industrial processes is the dehydrogenation of alcohols to their corresponding aldehydes and ketones that are widely used as fuel substitute sources, solvents, and chemical reaction intermediate compounds (Keuler et al., 2001). The dehydrogenation of 2butanol to methyl ethyl ketone (MEK) is one of the most important industrial processes due to the economical importance of MEK which has wide spectrum of applications. In addition to its use as fuel substitute, MEK is used also as solvent in the paint, adhesive industry, in surface coatings, removal of paints and varnish, printing inks, and as an extraction medium for oils, fats, resins and waxes (Hoppe et al., 2016).

In a part of a recent study in our laboratory (Halawy et al., 2021), pure nanocrystalline $\mathrm{NiO}$ catalyst was prepared by the thermal decomposition of a home-made nickel oxalate dihydrate produced from nickel carbonate basic hydrate and oxalic acid dehydrate. The NiO catalyst was tested for the production of MEK from 2-butanol and showed a good efficiency. In this study, as part of our endeavor to develop simple environment-friend preparation methods, a pure nanocrystalline $\mathrm{NiO}$ was prepared by the thermal decomposition of a pre-sonicated commercial $\mathrm{NiC}_{2} \mathrm{O}_{4} \cdot 2 \mathrm{H}_{2} \mathrm{O}$. This method is characterized by using cheap commercial salt instead of preparing it in the laboratory, which reduces costs and saves time. The prepared $\mathrm{NiO}$ catalysts were tested also as catalysts for the dehydrogenation of 2-butanol to MEK as an economically important test reaction.

\section{EXPERIMENTAL}

\subsection{Preparation of $\mathrm{NiO}$ samples}

Nickel oxalate dihydrtae $\mathrm{NiC}_{2} \mathrm{O}_{4} \cdot 2 \mathrm{H}_{2} \mathrm{O}$ powder was mixed with a little amount of de ionized water using ultrasonic bath at $70{ }^{\circ} \mathrm{C}$ to obtain a homogeneous paste which was left in the ultrasonic bath till dryness. The resulting material was dried at $120{ }^{\circ} \mathrm{C}$ for $24 \mathrm{~h}$ and was finally calcined in static air for $2 \mathrm{~h}$ at 400,500 and $600{ }^{\circ} \mathrm{C}$. Nickel oxalate samples calcined at 400, 500 and $600{ }^{\circ} \mathrm{C}$ were denoted as N400, N500 and N600, respectively. 


\subsection{Characterization of $\mathrm{NiO}$ samples}

Thermogravimetry (TG), and differnitial thermal analysis (DTA) were performed at heating rate $10^{\circ} \mathrm{C} / \mathrm{min}$ in a flow of $40 \mathrm{~cm}^{3} / \mathrm{min}$ dry nitrogen, using automatically recording model $50 \mathrm{H}$ Shimadzu thermal analyzer, Japan. The thermal analyzer is equipped with a data acquisition and handling system (TA-50WSI), while $\alpha$-alumina was used as the reference material in (DTA) measurements. IR spectra of the samples were recorded using a Magna-FT-IR 500 (USA), between $4000-300 \mathrm{~cm}^{-1}$, operating Nicolet Omnic software and adopting the $\mathrm{KBr}$ disk technique. X-ray powder diffraction analysis (XRD) was carried out using a model D5000 Siemens diffractometer (Germany), equipped with a copper anode generating Ni-filtered $\mathrm{Cu} K \alpha$ radiation $(\lambda=1.5406 \AA)$, in the $2 \theta$ range between $20^{\circ}$ and $80^{\circ}$. An on-line data acquisition and handling system facilitated an automatic JCPDS library search and match (Diffrac software, Siemens) for phase identification purposes. The BET surface area measurements were performed at liquid nitrogen temperature $\left(-195^{\circ} \mathrm{C}\right)$ using an automatic Gemini VII Micromeritics (USA) Model 2390P in Egyption ferroalloys company. The solid samples were outgassed at $200{ }^{\circ} \mathrm{C}$ for $1 \mathrm{~h}$ prior to measurements. Scanning electron microscopy (SEM) was used to analyze the morphology of the samples using JEOL JSM-IT200 SEM.

\subsection{Determination surface basicity of $\mathrm{NiO}$ samples}

The surface basicity of all the samples under investigation was studied quantitatively and qualitatively by means of desorption thermogravimetry using $\mathrm{CO}_{2}$ as a probe molecule. $50 \mathrm{mg}$ of each sample was pre-heated at $400^{\circ} \mathrm{C}$ for $1 \mathrm{hr}$ in static air, then; all the samples were kept for two weeks in a glass chamber fitted with gas inlet and outlet under a flow of $40 \mathrm{ml} / \mathrm{min} \mathrm{CO}_{2}$ gas. 15-20 mg of sample covered with adsorbed $\mathrm{CO}_{2}$ was subjected to TG analysis on heating till $400^{\circ} \mathrm{C}$ at a heating rate of 20 ${ }^{\circ} \mathrm{C} / \mathrm{min}$. The mass loss from TG analysis due to desorption of $\mathrm{CO}_{2}$ molecules from the basic sites was determined as a function of surface basic sites density. The temperature ranges of the mass loss steps were used as a measure of the strength of the basic sites. Calculation of the density of the basic sites expressed in (site/g) was carried out using the following equation (Osman et al., 2012):

Basicsite density (site/g) moles of $\mathrm{CO} 2$ desorped x Avogadro Number(sites/mol)

\section{weight of sample (g)}

\subsection{Catalytic activity measurements}

The catalytic activity of all the catalysts for the vapor phase dehydrogenation/dehydration of 2-butanol as indicated in scheme.1. (Halawy et al., 2021) was performed in a continuous flow system under atmospheric pressure. The reactions were carried out in a Pyrex glass reactor $(1 \mathrm{~cm}$ wide and $16.5 \mathrm{~cm}$ long) using nitrogen as a carrier gas. $200 \mathrm{mg}$ of the catalyst was preheated for one hour at $400^{\circ} \mathrm{C}$ under a flow of $100 \mathrm{ml} / \mathrm{min}$ nitrogen; then, the temperature was lowered to the reaction temperature. All catalysts were subjected to the reaction at saturator temperature $5{ }^{\circ} \mathrm{C}$ and weight hourly space velocity equal $30 \mathrm{Lh}^{-1} \mathrm{~g}^{-1}$ which give $(100 \mathrm{ml} / \mathrm{min}=0.789 \%$ secondary butanol $+99.211 \%$ nitrogen). The reactor effluent was analyzed by using a gas chromatograph (Shimadzu GC-14A) equipped with a data processor model Shimadzu chromatrope C-R4AD (Japan). A flame ionization detector (FID) and a stainless-steel column (PEG 20M 20\% on chromocarb W, 60/80 mesh, $3 \mathrm{~m} \times 3 \mathrm{~mm}$ ) at 
$80^{\circ} \mathrm{C}$ were used to identify secondary butanol and the reaction products. Automatic sampling was performed with a heated gas sample cock, type HGS-2 at $140{ }^{\circ} \mathrm{C}$.

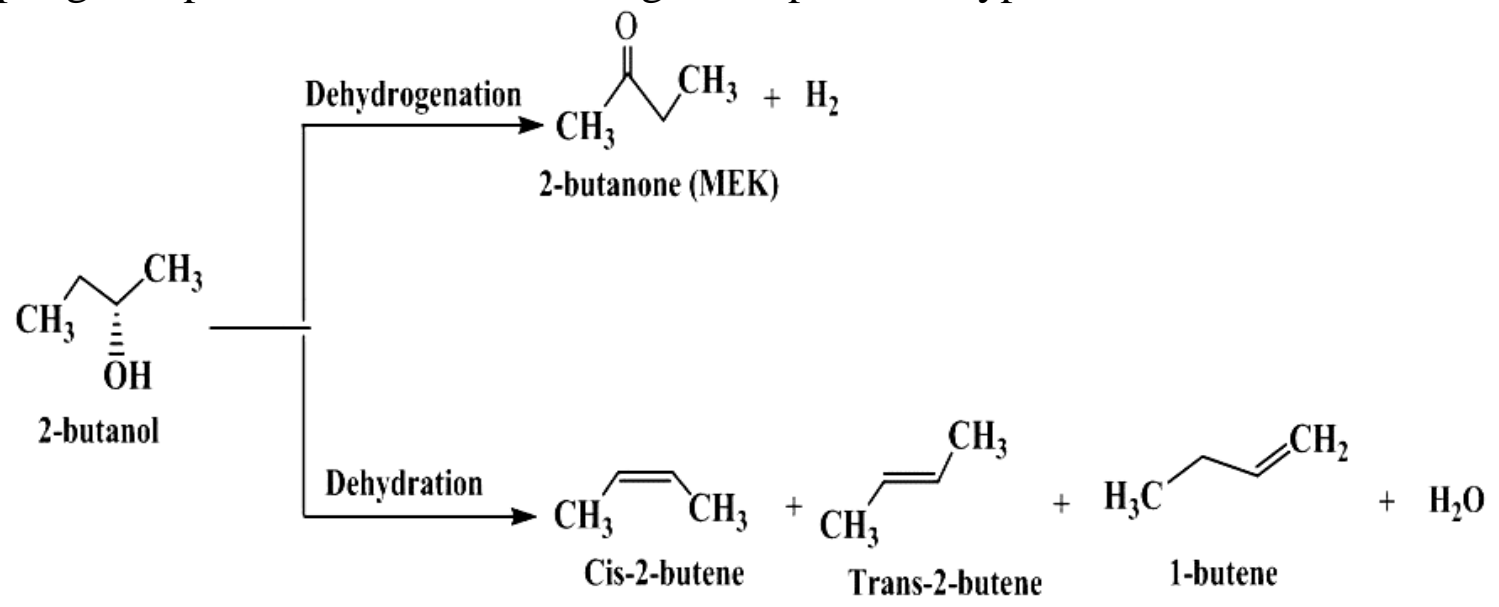

Scheme. 1. Catalytic decomposition (Dehydrogenation and Dehydration) of 2-butanol

\section{RESULT AND DISCUSSION}

\subsection{Catalyst characterization}

TG-DTA curves of pure nickel oxalate dihydrate $\left(\mathrm{NiC}_{2} \mathrm{O}_{4} \cdot 2 \mathrm{H}_{2} \mathrm{O}\right)$ precursor are shown in Figure 1. Two mass loss steps can be seen in the TG curve with $60.9 \%$ total mass loss. These two mass losses have two corresponding DTA endothermic peaks. The first step centered at $260{ }^{\circ} \mathrm{C}$ and associated with $21.4 \%$ mass loss which is likely due to the dehydration of nickel oxalate dihydrate to form anhydrous oxalate. The calculated theoretical value of the mass loss due to removing of two water molecules from nickel oxalate dihydrate was found to be $19.7 \%$ which is relatively similar to the experimental value. The second mass loss step started at $350{ }^{\circ} \mathrm{C}$ associated with $39.5 \%$ mass loss can be attributed to the decomposition of the anhydrous $\mathrm{NiC}_{2} \mathrm{O}_{4}$ to $\mathrm{NiO}$ which is theoretically associated with a mass loss of $39.4 \%$.

Figure 2 shows the FT-IR spectra obtained for nickel oxalates and its calcination products. Spectrum (a) of pure Ni-oxalates shows peaks at 3400-3450, 1628, 1360-1364, 1315, 830, 760, 615-620, 530 and 460-480 $\mathrm{cm}^{-1}$ assigned to $v(\mathrm{OH}), v$ as of $\mathrm{C}=\mathrm{O}, v \mathrm{~s} \mathrm{C}-\mathrm{O}+\mathrm{v}(\mathrm{C}-\mathrm{C})$, vs $\mathrm{C}-\mathrm{O}+\delta(\mathrm{O}-\mathrm{C}=\mathrm{O})$, vs $\mathrm{C}-\mathrm{O}+\delta(\mathrm{O}-\mathrm{C}=\mathrm{O}), \delta(\mathrm{O}-\mathrm{C}=\mathrm{O})+v(\mathrm{Ni}-\mathrm{O}), v(\mathrm{O}-\mathrm{Ni}-\mathrm{O}), v(\mathrm{Ni}-\mathrm{O})+v(\mathrm{C}-$ $\mathrm{C})$ and $v(\mathrm{Ni}-\mathrm{O})$ respectively (Donia., 1997; Li et al., 2001). Spectrum (b) of N400 shows pure $\mathrm{NiO}$ with uni- and bidentate surface carbonate due to $\mathrm{CO}_{2}$ adsorption. Spectrum (c, d) of N500 and N600 shows only pure $\mathrm{NiO}$.

Figure 3 shows the XRD diffractograms of the prepared $\mathrm{NiO}$ samples. The three diffractograms showed the same five diffraction peaks and was indexed as (111), (200), (220), (311) and (222) crystal planes correspond to cubic NiO phase (JCPDS 78-0423). It is clear from the XRD diffractograms in figure 3 that the calcination temperature has a notable effect on the crystallinity of the prepared $\mathrm{NiO}$ samples as the peak sharpness increased by increasing the calcination temperature. A small peak at 2theta of 44.56 started to appear in the N500 sample which increased by increasing calcination temperature in N600 with the appearance of another at 2 theta of 52. These two peaks are attributed to metallic nickel (ICDD, 004-0850) which is formed 
likely due to the reduction of a finite amount of $\mathrm{NiO}$ by carbon deposition during the decomposition oxalate salt (Cheng et al., 2016; Cao et al., 2006).

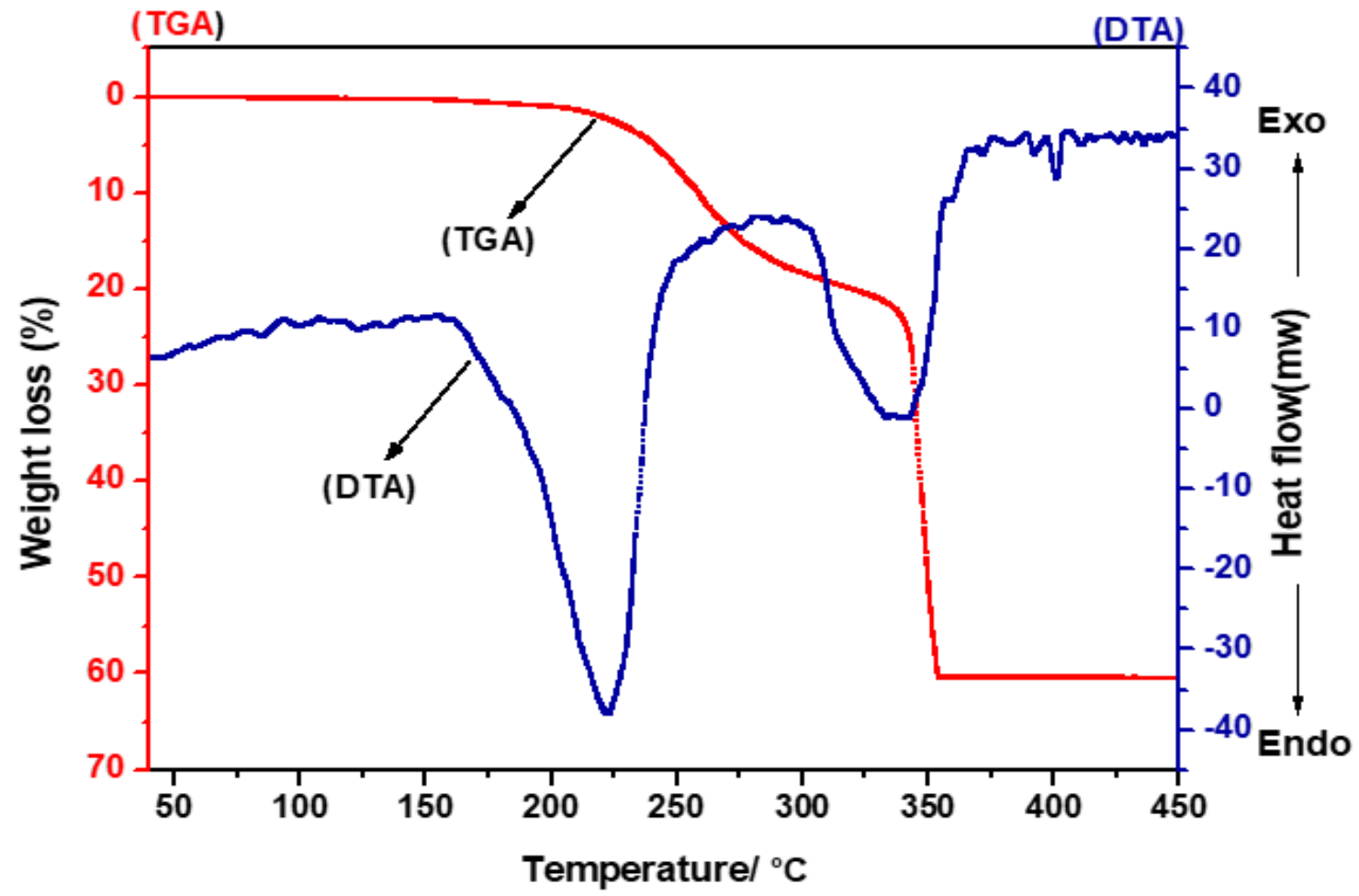

Fig.1. TGA and DTA curves of nickel oxalate dihydrate carried out at a heating rate of $10^{\circ} \mathrm{C} / \mathrm{min}$ in nitrogen atmosphere of $40 \mathrm{ml} / \mathrm{min}$.

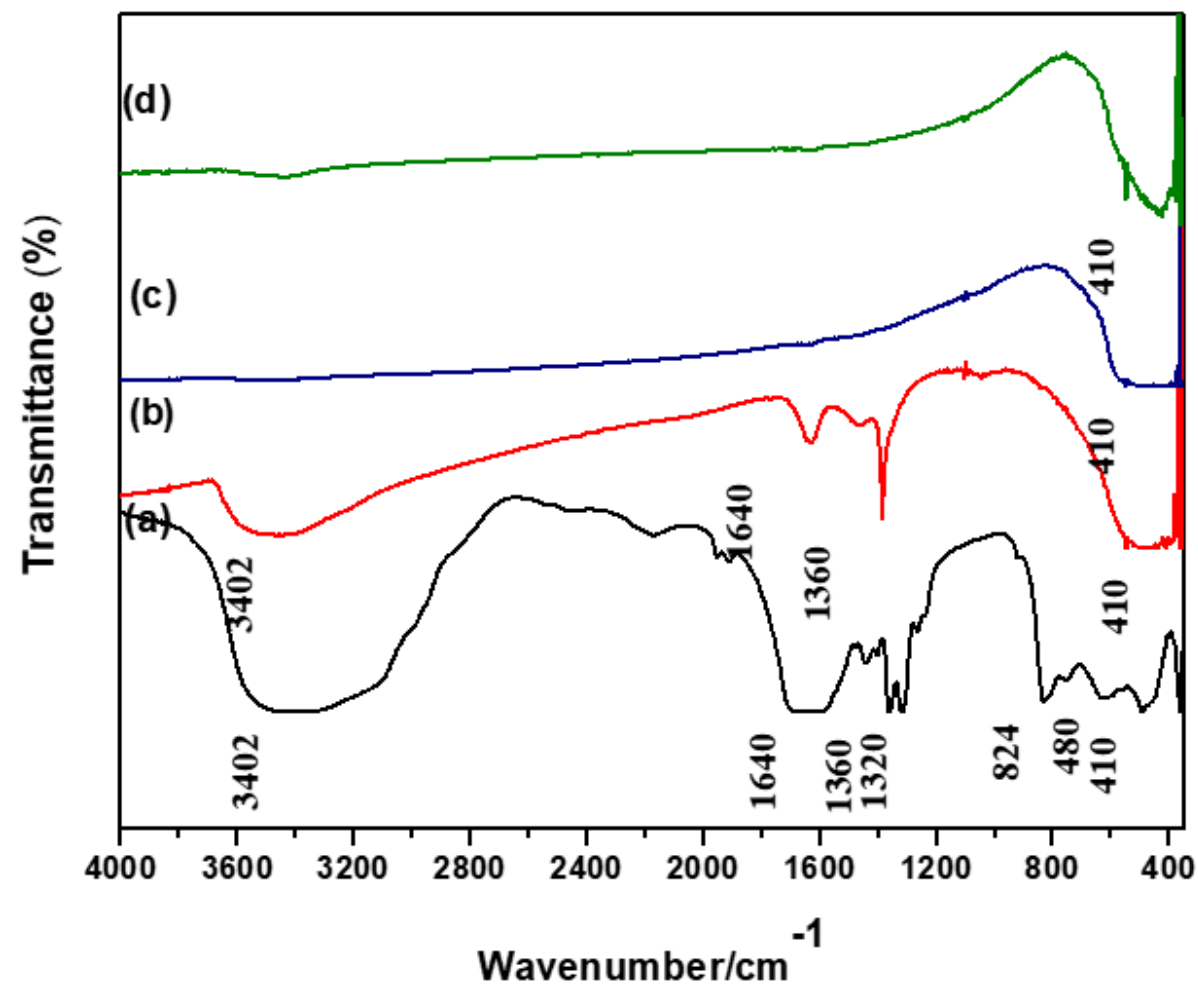

Fig.2. FT-IR spectra nickel oxalate dihydrateand (N400, N500, N600), (a, b, c, d) respectively. 


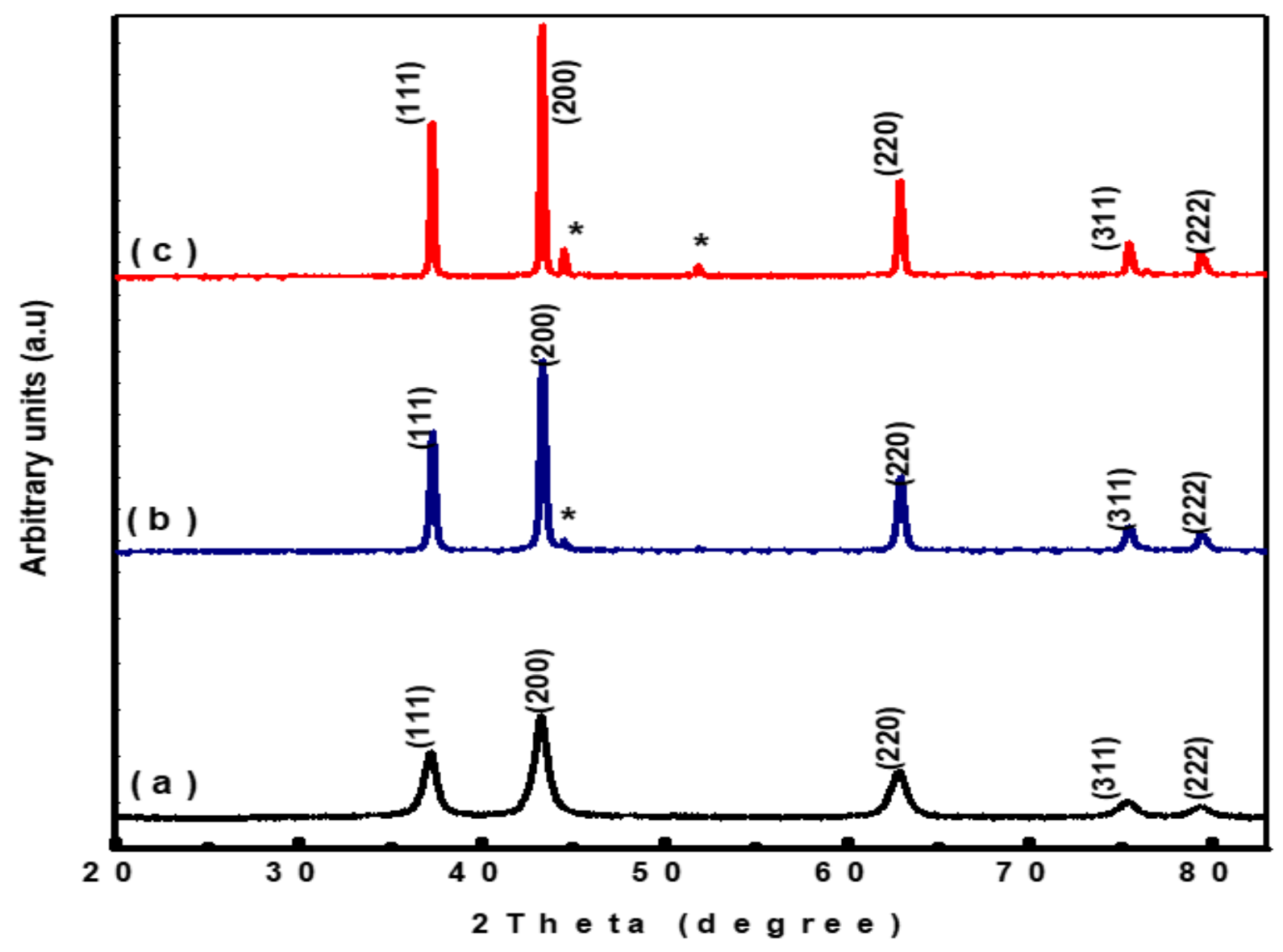

Fig.3. XRD patterns of (N400, N500, N600) samples, (a, b, c) respectively.

Figure 4 shows the SEM images of the prepared $\mathrm{NiO}$ samples. It is clear from figure 4 that the morphologies of $\mathrm{NiO}$ are changed with calcination temperature. Both of N400 and N500 sample images shows a one-dimensional rod-like morphology with a partial agglomeration started to appear in N500 sample due to increasing calcination temperature. By increasing the calcination temperature to $600^{\circ} \mathrm{C}$ in $\mathrm{N} 600$, the rod-like particles are completely agglomerated to form compact granules. Table.1. shows the results of BET surface area, Total number of basic sites and average crystallite size of the prepared $\mathrm{NiO}$ samples. As expected, the increase in calcination temperature significantly decreased the surface area and surface basicity of $\mathrm{NiO}$ samples while increased their crystallite size. It was surprising to find that the N400 sample has better properties than the nickel oxide sample in our recent study which was calcined at $400^{\circ} \mathrm{C}$ (Halawy, et al., 2021) values of surface area, total number of basic sites and average crystallite size for N400 $\left(68.98 \mathrm{~m}^{2} / \mathrm{g}, 4.28 \times 1020 \mathrm{site} / \mathrm{g}\right.$ and $\left.11.65 \mathrm{~nm}\right)$ is better than that of nickel oxide sample in our previous research $\left(63.3 \mathrm{~m}^{2} / \mathrm{g}, 2.84 \times 10^{20} \mathrm{site} / \mathrm{g}\right.$ and $\left.12.5 \mathrm{~nm}\right)$. 
Table. 1. Crystallite size, total surface area measurement (BE T), and total number of basic sites (site/g)

\begin{tabular}{|c|c|c|c|}
\hline Sample & C. size $(\mathrm{nm})$ & $\mathrm{S}_{\text {BET }}\left(\mathrm{m}^{2} / \mathrm{g}\right)$ & $\begin{array}{c}\text { Total no. of basic } \\
\text { sites }(\mathrm{site} / \mathrm{g})\end{array}$ \\
\hline N400 & 11.65 & 68.98 & $4.283 \times 10^{20}$ \\
\hline N500 & 30.64 & 5.711 & $0.458 \times 10^{20}$ \\
\hline N600 & 44.79 & 0.5942 & $0.284 \times 10^{20}$ \\
\hline
\end{tabular}

\subsection{Catalytic activity measurements}

The catalytic activity of the prepared $\mathrm{NiO}$ catalysts calcined at different temperatures was tested during the decomposition of secondary butanol (dehydrogenation and dehydration) in a reaction temperature range of $225-325^{\circ} \mathrm{C}$. Figure 5 shows the $\%$ conversion of secondary butanol over all the tested $\mathrm{NiO}$ catalysts as a function of reaction temperature. As shown in Figure 5, the $\%$ conversion increases by increasing reaction temperature for all the catalysts which can be attributed to gradual activation of the $\mathrm{NiO}$ surface active sites by increasing the reaction temperature (Halawy, et al., 2021). The effect of calcination temperatures of $\mathrm{NiO}$ catalysts on their catalytic activity is clear from the notable decrease in the \% conversion by increasing the calcination temperature as shown in Figure $\mathbf{5}$ where the order of catalytic activity is $\mathrm{N} 400>\mathrm{N} 500 \approx \mathrm{N} 600$. This decrease in the catalytic activity with the increase in calcination temperature is expected as a result of the sharp decrease in both of the surface area and number of basic sites in the same direction especially in the $400^{\circ} \mathrm{C}-500^{\circ} \mathrm{C}$ transition as shown in Table 1. Also the catalytic activity of the prepared $\mathrm{NiO}$ catalysts can be attributed to the combination of two factors; the surface area and the presence of metal/oxide interface. By increasing the calcination temperature, the surface area decreases while the number of metal/oxide $(\mathrm{Ni} / \mathrm{NiO})$ points increase in the same direction which maintain the catalytic activity of $\mathrm{NiO}$ catalysts at a relatively good level (Halawy, et al.,2021).

The effect of weight-hourly-space-velocity (WHSV) on the catalytic activity of the N400 catalyst, as the most active one, was investigated in a temperature range of $225-325^{\circ} \mathrm{C}$ and using three values WHSV (i.e. 15, 30 and $60 \mathrm{~L} \mathrm{~h}^{-1} \mathrm{~g}^{-1}$ ) and the results are shown in Figure 6. According to the results in Figure 6, the values of \% conversion decreased clearly by increasing the value of WHSV which can be attributed to the decrease in the contact time between the reacting molecules and surface-active sites. A test of stability and reusability of the $\mathrm{N} 400$, as the most active catalyst, was carried out by repeating the full catalytic test over $225-325^{\circ} \mathrm{C}$ temperature range four times using the same catalyst bed. Each cycle takes about 5 hours and a refreshment step was applied before each new cycle by heating the catalyst at $400^{\circ} \mathrm{C}$ for 1 hour in a flow of nitrogen. The stability test results are shown in figure 7 where we can see clearly that the four cycles are relatively identical which indicate that the catalyst is stable and reusable. 

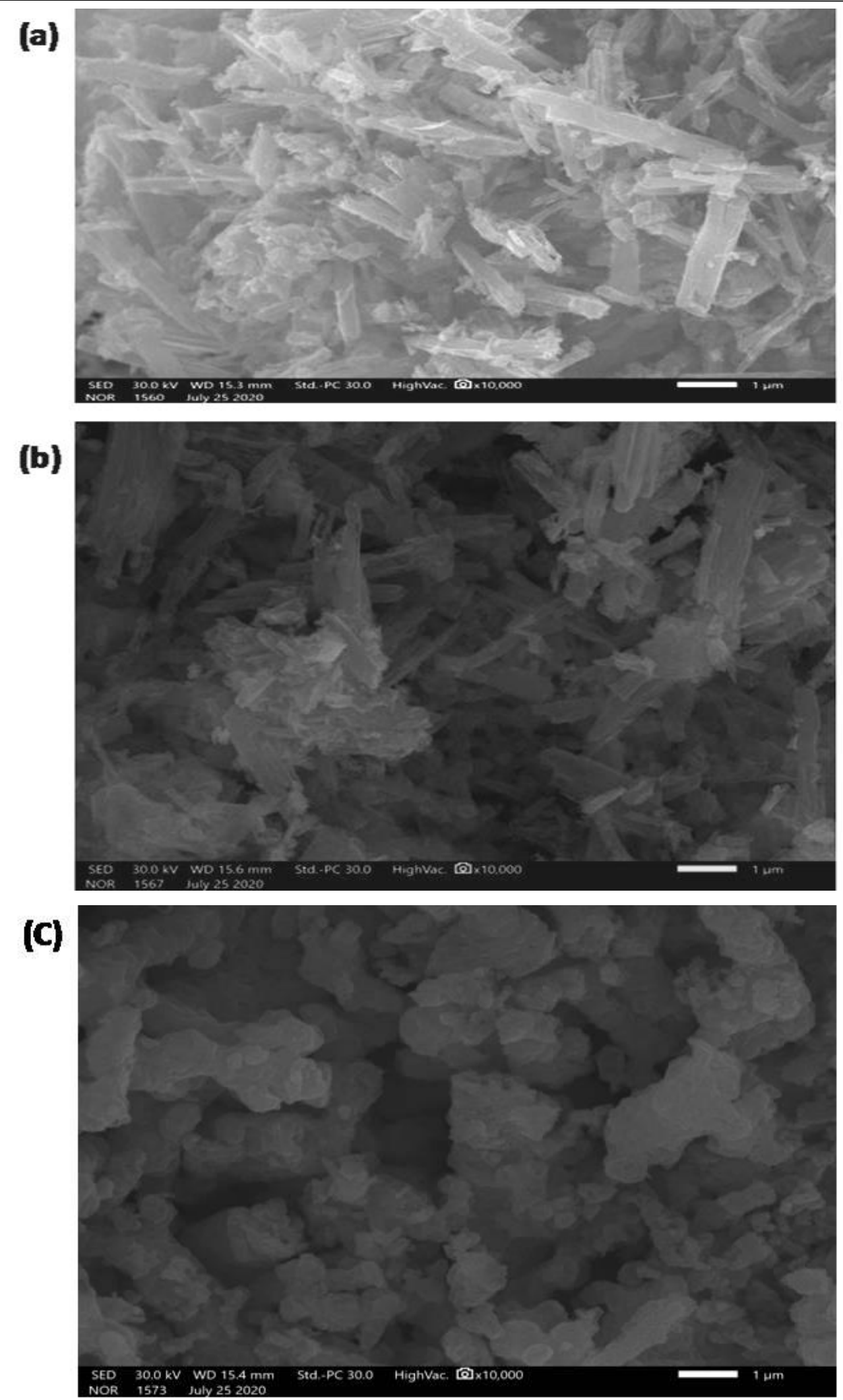

Fig. 4. SEM images for N400(a), N500(b) and N600 (c) at magnification 10000x. 


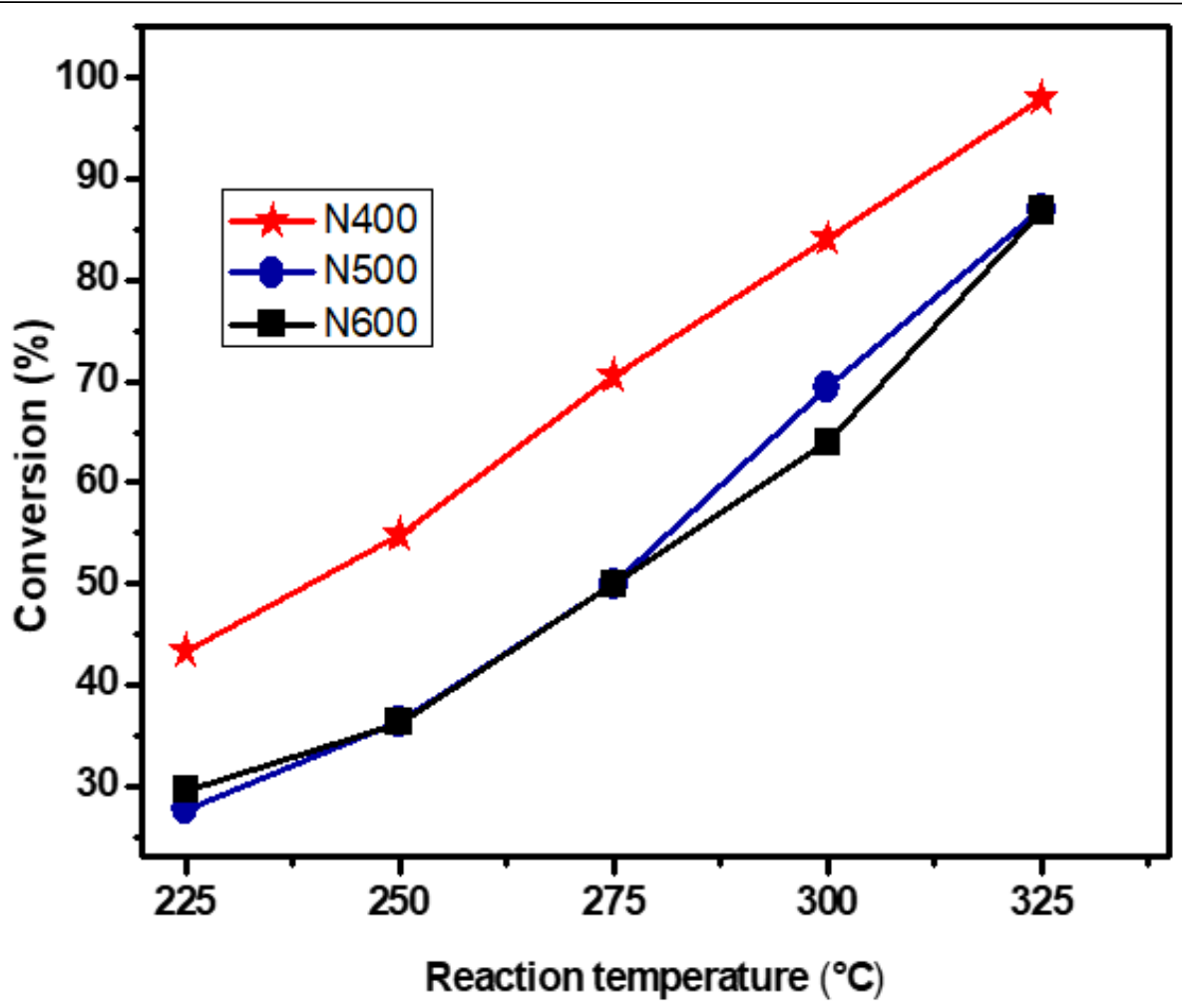

Fig. 5. Catalytic activity profiles for sec-butanol decomposition over (N400, N500, N600) samples at temperature range $(225: 325){ }^{\circ} \mathrm{C}$.

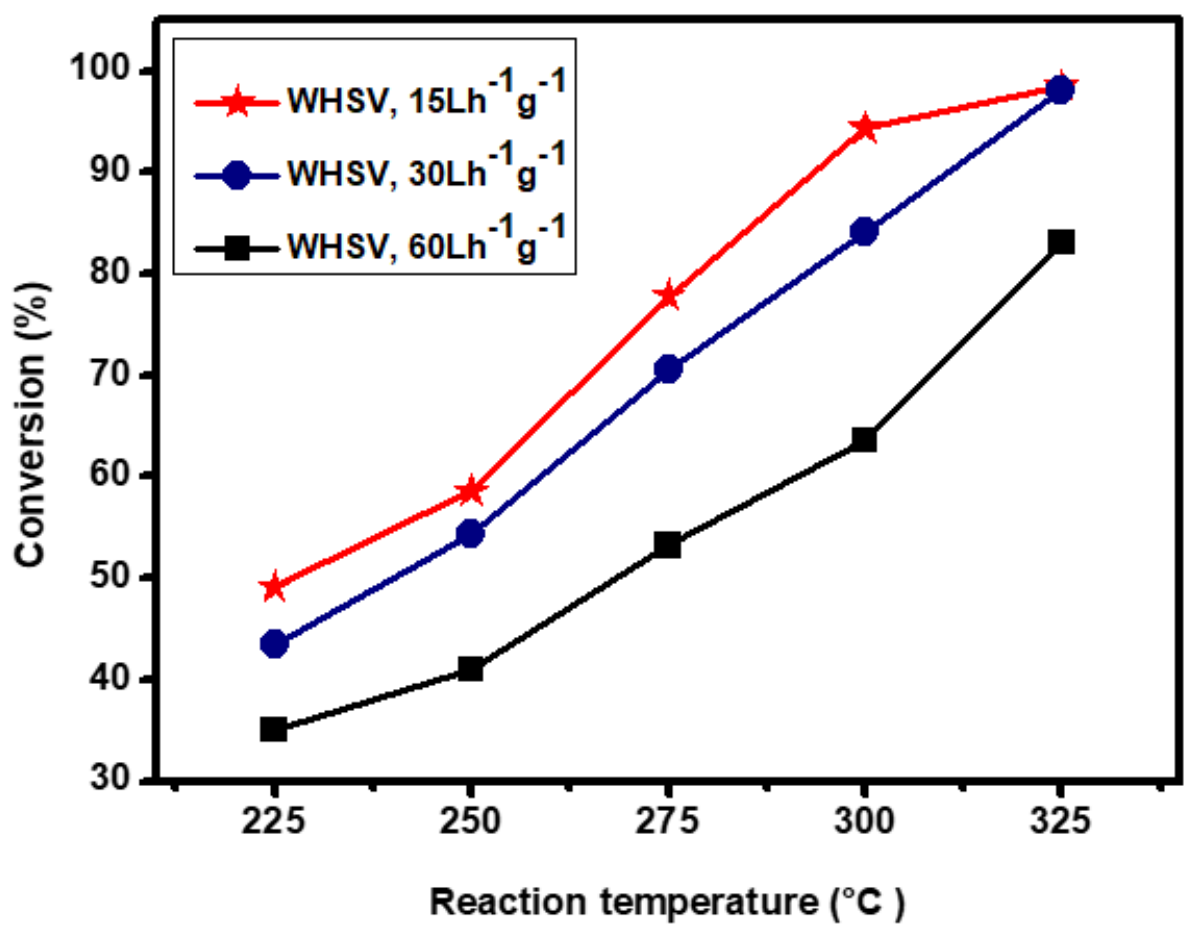

Fig .6. effect of gas houriy space velocity on catalytic activity of N400 sample at temperature range $(225: 325)^{\circ} \mathrm{C}$. 


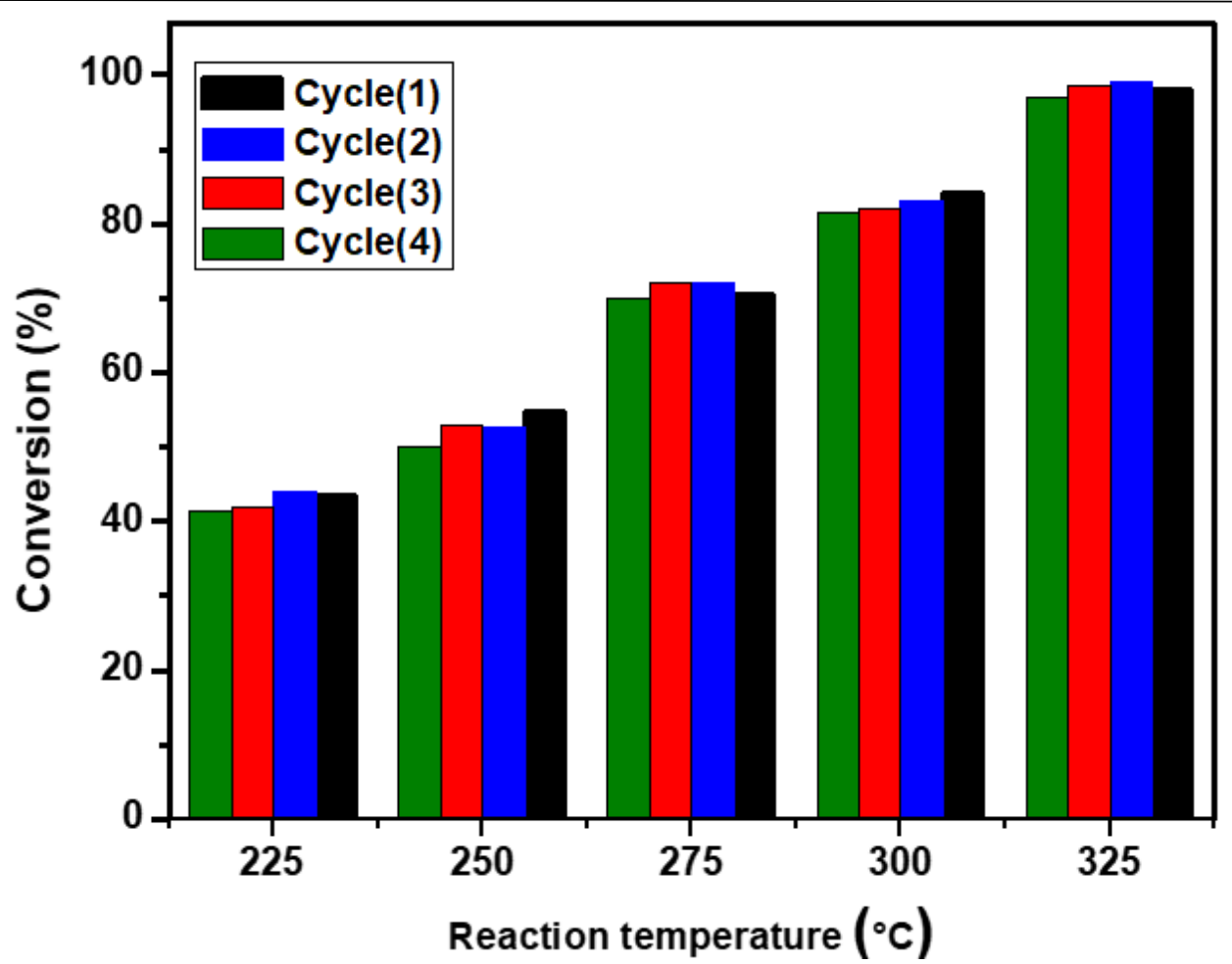

Fig.7. Comparison of catalytic activity between fresh N400 and regenerated N400 during the conversion of sec butanol at reaction temperature range of $200-325^{\circ} \mathrm{C}$.

\section{Conclusion}

Nanocrystalline $\mathrm{NiO}$ catalysts were prepared by the thermal treatment of commercial nickel oxalate dihydrate. The results indicated that the calcination temperature of the nickel oxalate dihydrate precursor strongly affected the morphology, the surface properties and consequently the catalytic activity of the produced $\mathrm{NiO}$ catalysts. The sample $\mathrm{N} 400$ calcined at $400^{\circ} \mathrm{C}$ is the best in terms of surface area, number of basic centers and consequently catalytic activity toward the dehydrogenation of 2-butanol. By increasing the calcination temperature, the $\mathrm{NiO}$ catalysts showed a notable decrease in both of surface area and number of basic centers which decreased their catalytic activity. In conclusion, the preparation method presented in this work offers a simple and cost-effective way for the production of nanocrystalline nickel oxide catalysts.

\section{References}

Abbasi MA, Ibupoto ZH, Khan A, Nur O, Willander M (2013) Fabrication of photo-detector based on coral reef like p-NiO/n-ZnOnanocomposite structures. Materials Letters, 108, 149-152.

Al-Ghamdi AA, Abdel-Wahab MS, Farghali AA, Hasan PM (2016) Structural, optical and photo-catalytic activity of nanocrystallineNiO thin films. Materials Research Bulletin, 75, 71-77.

Alloun A, Nair CG (1985) Thermal decomposition kinetics for Nickel/II/Oxalate-dihydrate. Thermochimica acta, 92, 767-769. 
Bodurov G, Stefchev P, Ivanova T, Gesheva K (2014) Investigation of electrodeposited $\mathrm{NiO}$ films as electrochromic material for counter electrodes in "Smart Windows". Materials Letters, 117, 270-272.

Bonomo, M. (2018). Synthesis and characterization of NiO nanostructures: a review. Journal of Nanoparticle Research, 20(8), 1-26.

Cao Y, Casenas B, Pan WP (2006) Investigation of chemical looping combustion by solid fuels. 2. Redox reaction kinetics and product characterization with coal, biomass, and solid waste as solid fuels and $\mathrm{CuO}$ as an oxygen carrier. Energy \& Fuels 20(5):1845-1854.

Cheng F, Dupont V, Twigg MV (2016) Temperature-programmed reduction of nickel steam reforming catalyst with glucose. Applied Catalysis A: General, 527, 1-8.

Donia AM (1997) Synthesis, identification and thermal analysis of coprecipitates of silver(cobalt, nickel, copper and zinc) oxalate. Polyhedron 16(17):3013-3031.

Halawy SA, Osman AI, Abdelkader A, Yang H (2021) Boosting NiO Catalytic Activity by x wt\% F-ions and $\mathrm{K}_{2} \mathrm{O}$ for the Production of Methyl Ethyl Ketone (MEK) via Catalytic Dehydrogenation of 2-Butanol. ChemCatChem. 13, 2200-2214

Halawy SA, Mohamed MA, Abdelkader A (2018) Hierarchical nanocrystallineNiO with corallike structure derived from nickel galactaratedihydrate: An active mesoporous catalyst for methyl ethyl ketone production. Arabian Journal of Chemistry, 11(6), 991-999.

Hoppe F, Burke U, Thewes M, Heufer A, Kremer F, Pischinger S (2016) Tailor-Made Fuels from Biomass: Potentials of 2-butanone and 2-methylfuran in direct injection spark ignition engines. Fuel, 167, 106-117.

Keuler JN, Lorenzen L, Miachon S (2001) The dehydrogenation of 2-butanol over copper-based catalysts: optimising catalyst composition and determining kinetic parameters. Applied Catalysis A: General, 218(1-2), 171-180.

Kundu M, Karunakaran G, Kuznetsov D (2017) Green synthesis of NiO nanostructured materials using Hydrangea paniculata flower extracts and their efficient application as supercapacitor electrodes. Powder Technology, 311, 132-136.

Li GJ, Huang XX, Shi Y, Guo JK (2001) Preparation and characteristics of nanocrystallineNiO by organic solvent method. Materials Letters, 51(4), 325-330.

Li H, Ma H, Yang M, Wang B, Shao H, Wang L, Yu R, Wang D (2017) Highly controlled synthesis of multi-shelled $\mathrm{NiO}$ hollow microspheres for enhanced lithium storage properties. Materials Research Bulletin, 87, 224-229.

Lu Y, Ma Y, Ma S, Yan S (2017) Hierarchical heterostructure of porous NiOnanosheets on flower-like $\mathrm{ZnO}$ assembled by hexagonal nanorods for high-performance gas sensor. Ceramics International, 43(10), 7508-7515.

Mansour SA (1993) Spectroscopic and microscopic investigations of the thermal decomposition course of nickel oxysalts: Part 3. Nickel oxalate dihydrate. Thermochimica acta, 230, 243257.

Mohamed MA, Galwey AK, Halawy SA (2005) A comparative study of the thermal reactivities of some transition metal oxalates in selected atmospheres. Thermochimica acta, 429(1), 57-72.

Mu J, Perlmutter DD (1981) Thermal decomposition of carbonates, carboxylates, oxalates, acetates, formates, and hydroxides. Thermochimica Acta, 49(2-3), 207-218. 
Osman AI, Abu-Dahrieh JK, Rooney DW, Halawy SA, Mohamed MA, Abdelkader A (2012) Effect of precursor on the performance of alumina for the dehydration of methanol to dimethyl ether. Applied Catalysis B: Environmental, 127, 307-315.

Tyagi M, Tomar M, Gupta V (2014) Glad assisted synthesis of NiOnanorods for realization of enzymatic reagentless urea biosensor. Biosensors and Bioelectronics, 52, 196-201.

Wang Z, Cui J, Li J, Cao K, Yuan S, Cheng Y, Wang M (2015) Surface plasma resonance enhanced photocurrent generation in NiOphotoanode based solar cells. Materials Science and Engineering: B, 199, 1-8.

Yong WJ, Hall B (1989) The thermal decomposition of nickel oxalates doped with traces of other metal ions. Thermochimica Acta, 147(2), 251-260.

Zhang H, Liu S (2017) Nanoparticles-assembled NiOnanosheetstemplated by graphene oxide film for highly sensitive non-enzymatic glucose sensing. Sensors and Actuators B: Chemical, 238, 788-794

Zhang S, Yin B, Wang Z, Peter F (2016) Super long-life all solid-state asymmetric supercapacitor based on NiOnanosheets and $\alpha-\mathrm{Fe}_{2} \mathrm{O}_{3}$ nanorods. Chemical Engineering Journal, 306, 193-203

Zhang Y (2015) Study of Schottky contact between $\mathrm{Au}$ and $\mathrm{NiO}$ nanowire by conductive atomic force microscopy (C-AFM): The case of surface states. Physica E: Low-dimensional Systems and Nanostructures, 69, 109-114

Zhang Y, Wang S, Chen L, Fang Y, Shen H, Du Z (2017) Solution-processed quantum dot lightemitting diodes based on NiOnanocrystals hole injection layer. Organic Electronics, 44, 189-197.

Zhao, Y., Zhang, X., Xu, X., Zhao, Y., Zhou, H., Li, J., \& Jin, H. (2016). Synthesis of NiO nanostructures and their catalytic activity in the thermal decomposition of ammonium perchlorate. CrystEngComm, 18(25), 4836-4843.

Zhou K, Qi Z, Zhao B, Lu S, Wang H, Liu J, Yan H (2017) The influence of crystallinity on the electrochromic properties and durability of $\mathrm{NiO}$ thin films. Surfaces and Interfaces, 6, 9197. 